\section{Military Technical College Kobry El-Kobbah, Cairo, Egypt}

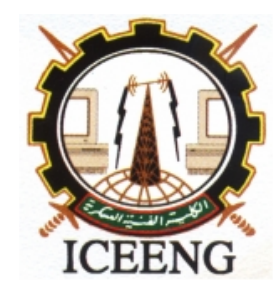

\title{
Modern Wind Turbines
}

\author{
By \\ Amged S. El-Wakeel \\ Usama R. AbouZayed \\ Reda Yousef \\ W. Sabry \\ Egyptian Armed Forces
}

Egypt

\section{$8^{\text {th }}$ International Conference on Electrical Engineering \\ ICEENG 2012}

\section{$\underline{\text { Abstract: }}$}

The main goal of this work is to present a design and implementation of a modern wind turbine. It can be installed on the rooftop of residential and commercial buildings and generate electric power from low speed wind energy. By this way, it becomes suitable for urban and isolated areas and those areas in which traditional large wind turbines are not practical. The main principal of it is to amplify; nearly duplicate, the ambient wind speed using wind tunnel effect. Theoretically, doubling the wind speed with tunnel effect increases the generated electric energy by a factor of eight. It can operate at ambient wind speeds of as low as four meters per second. In this work, the wind turbine is equipped with a $10 \mathrm{kVA}$ Permanent Magnet DC (PMDC) Generator and all the necessary equipment for conditioning the output power. It can be used as off-grid power source; which is suitable for isolated places. The whole system is implemented and tested at one of the commercial buildings in Shark El-Ewinat (Far Egyptian South-East deserts). The design and implementation results will be demonstrated. Future work will be presented in the last section. 